\title{
Editorial
}

\section{Stress in Medical Students: Is There Any Way Out?}

\author{
Firdous Jahan \\ Associate Professor/Chair, Family Medicine Department, Oman Medical College, Sultanate of Oman
}

Stress is the body's automatic response to any physical or mental stress and demand placed. The WHO projected that in 2020 mental illness will be the second leading contributor to the global burden of diseases [1]. Medical education is very demanding now days. Burden of information in medical profession and lots of competition make students anxious and depressed. The main goal and objective of medical curriculum is to provide competent and safe doctors to community. Training during medical college may effect on medical students' mental and emotional health [2]. Stress results when mental pressure exceeds their ability to cope. Some time it does not follow a potential stressor. Academic stress is a normal phenomenon and beneficial that can help one learn and grow. Studies suggest that excess of distress subsequently may affect students' learning process which ultimately affects care of patients, relationship with faculty and family members [3].

Literature has been reported stress and depression in medical students is because of high expectations, academic curriculum, exams, performance in periodic examinations, and worries of the future [4]. Stressors of medical student's generally academic related stressors, therefore, early detection of stressors among medical students may prevent unwanted consequences on their health and improve their academic performance [5].

Coping strategies are specific efforts to manage stress both behavioral and psychological. Medical students should learn how to handle stress and anxiety so they can tolerate or minimize stressful events [6]. Previous studies showed that coping plays a central role in adaptation to stressful life events. Stress reduction and adopting a healthier life style have been major concerns of the students. Excessive anxiety and mental stress may affect their learning ability and academic performance [7]. Stress can be best managed by regular exercise, meditation or other relaxation techniques, structured time outs and learning new coping strategies to handle stress in medical students [8]. Training for stress handling should start even before joining medical school. Students learning environment and family background are the main underlying causes of anxiety and depression in medical students super added by the stress induced by medical curriculum. Self-regulation of effort, time, and study environment can positively influence academic achievements.

\section{REFERENCES}

1. World Health Organization (WHO) [Mental Health: Depression]. Geneva (CH): WHO; 2003. [cited 2010 August 28]. [Internet] Available from: http://www.who.int/mental_ health/management/depression/definition/en/index.html.

2. Abdulghani HM. Stress and depression among medical students: A cross sectional study at a medical college in Saudi Arabia. Pak J Med Sci. 2008; 24(1):12-17.

3. Zakiya Al-Busaidi, Kamlesh Bhargava, Aida Al-Ismaily, Hadia Al-Lawati, Rahma Al-Kindi, Mohammad Al-Shafaee, Abdullah Al-Maniri. Prevalence of Depressive Symptoms among University Students in Oman. Oman Medical Journal (2011) Vol. 26, No. 4: 235-239 DOI 10. 5001/omj.2011.58

4. Lee J, Graham A. Students' perception of medical school stress and their evaluation of a wellness elective. Med Educ. 2001;35:652-9.

5. Niemi PM and Vainiomaki PT. Medical students' distress quality, continuity and gender differences during a six-year medical program. Med Teach, 2006; 28(2): 136-141.

6. Sherina MS, Lekhraj R and Nadarajan K. Prevalence of emotional disorder among medical students in a Malaysian university, Asia Pacific Family Medicine, 2003; 2: 213-217.

7. Oku AO, Owoaje ET, Oku OO, Ikpeme BM. Prevalence of stress, stressors and coping strategies among medical students in a Nigerian medical school. Afr J Med Health Sci 2015;14(1):29-34.

8. Mona Soliman. Perception of stress and coping strategies by medical students at King Saud University, Riyadh, Saudi Arabia. Journal of Taibah University Medical Sciences .March 2014; 9(1): 30-35.

\section{ADDRESS FOR CORRESPONDENCE}

Dr Firdous Jahan, Associate Professor/Head of the Department, Family Medicine, Oman Medical College, Sohar, Sultanate of Oman, E-mail: firdous@omc.edu.om 